\title{
In vitro and in vivo reversal of resistance to 5-fluorouracil in colorectal cancer cells with a novel stealth double-liposomal formulation
}

\author{
R Fanciullino', S Giacometti', C Mercier', C Aubert', C Blanquicett ${ }^{2}$, P Piccerelle ${ }^{3}$ and J Ciccolini*,I \\ 'EA3286-Laboratoire de Pharmacocinétique, Université de la Méditerranée, Marseille, France; ${ }^{2}$ Department of Medicine, School of Medicine, Emory \\ University, Atlanta, GA, USA; ${ }^{2}$ Laboratoire de Pharmacie Galénique, Faculté de Pharmacie, 27 Bd Jean Moulin, Marseille 05 I3385, France
}

\begin{abstract}
Drug resistance is a major cause of treatment failure in cancer chemotherapy, including that with the extensively prescribed antimetabolite, 5-fluorouracil (5-FU). In this study, we tried to reverse 5-FU resistance by using a double-punch strategy: combining 5-FU with a biochemical modulator to improve its tumoural activation and encapsulating both these agents in one same stealth liposome. Experiments carried out in the highly resistant, canonical SW620 human colorectal model showed a up to $80 \%$ sensitisation to 5-FU when these cells were treated with our liposomal formulation. Results with this formulation demonstrated $30 \%$ higher tumoural drug uptake, better activation with increased active metabolites including critical-5-fluoro-2-deoxyuridine-5-monophosphate, superior inhibition (98\%) of tumour thymidylate synthase, and subsequently, higher induction of both early and late apoptosis. Drug monitoring showed that higher and sustained exposure was achieved in rats treated with liposomal formulation. When examined in a xenograft animal model, our dual-agent liposomal formulation caused a $74 \%$ reduction in tumour size with a mean doubling in survival time, whereas standard 5-FU failed to exhibit significant antiproliferative activity as well as to increase the lifespan of tumour-bearing mice. Taken collectively, our data suggest that resistance to 5-FU can be overcome through a better control of its intratumoural activation and the use of an encapsulated formulation.
\end{abstract}

British Journal of Cancer (2007) 97, 919-926. doi:I0.1038/sj.bjc.6603970 www.bjcancer.com

Published online II September 2007

(c) 2007 Cancer Research UK

Keywords: stealth liposome; 5-FU; modulation; resistance; xenografts

Despite the fact that 5-fluorouracil (5-FU) has been in use for half a century, it remains the gold standard for chemotherapy of colorectal cancer, the third cause of death due to cancer worldwide. With a mere $20 \%$ response rate when used as monotherapy, numerous attempts have been made to improve its therapeutic index, both at the bench and at the bedside. 5Fluorouracil was rationally designed to target thymidylate synthase (TS), an enzyme that is essential for DNA synthesis and cell proliferation; however, the biochemical mechanisms responsible for its antitumour properties are complex and actually require anabolism of this prodrug into specific 5-FU nucleotides within cancer cells. Several enzymes involved in its metabolic activation eventually lead to the formation of active cytotoxic nucleotides or deoxynucleotides (Boyer et al, 2004). However, the major mechanism for 5-FU cytotoxicity is the formation of competitive 5fluoro-2-deoxyuridine-5-monophosphate (FdUMP), thereby inhibiting TS activity with subsequent depletion of intracellular thymidine, suppression of DNA synthesis, and ultimately,

\footnotetext{
*Correspondence: Dr J Ciccolini, EA3286, Laboratoire de Pharmacocinétique, Faculté de Pharmacie, 27 Bd Jean Moulin 13385, Marseille 05, France; E-mail: jo.ciccolini@pharmacie.univ-mrs.fr

Revised 18 July 2007; accepted 10 August 2007; published online II September 2007
}

apoptosis induction (Pinedo and Peters, 1988; Diasio and Harris, 1989; Langley et al, 2003). Overexpression of TS has been demonstrated to be associated with 5-FU resistance in patients with colorectal cancer (Johnston et al, 1995; Peters et al, 2002). In this respect, controlling the pattern of 5-FU activation, preferentially towards inhibiting TS FdUMP synthesis, is a major goal for optimising its anticancer efficacy.

The key enzyme in the process of yielding intratumoural FdUMP is thymidine phosphorylase (TP), the rate-limiting enzyme in the activation of 5-FU via the DNA pathway (Ciccolini et al, 2001; De Bruin et al, 2004). Several attempts to boost tumoural TP levels have been published in an effort to improve cell sensitivity to 5 -FU or oral 5-FU (capecitabine), by using either 'Suicide Gene' strategies (Schwartz et al, 1995a,b; Evrard et al, 1999; Ciccolini et al, 2001), co-treating tumour cells with modulators such as IFN, taxoïd drugs, mitomycine $\mathrm{C}$, or with radiotherapy (Ciccolini et al, 2004; Blanquicett et al, 2005). Among the numerous compounds tested as putative modulators, $2^{\prime}$-deoxyinosine (d-Ino) is a nontoxic precursor of the TP cofactor, deoxyribose 1-phosphate, that has been shown to enhance 5-FU's antiproliferative activity in several in vitro and in vivo models, when either used alone or combined with gene therapy strategies targeting TP (Ciccolini et al, 2000a, b; Fanciullino et al, 2006). So far, extensive erythrocytic metabolism and a failure to improve its pharmacokinetic profile have prevented d-Ino from being considered 
clinically, as a possible modulator of 5-FU. To achieve this goal, our group previously developed the first encapsulated formulation of d-Ino alone (d-InoL), which was designed to spare it from erythrocytic clearance. This d-InoL proved to increase 5-FU efficacy in vitro and in mice xenografts, at doses much lower than the ones used thus far (Fanciullino et al, 2005). The purpose of the present study was to develop a novel, stealth double-liposomal formulation encapsulating both 5-FU and its modulator, d-Ino, to enhance further the therapeutic index of 5-FU through a twopronged strategy: modulation + controlled release.

\section{MATERIALS AND METHODS}

\section{Cell lines}

All experiments were carried out in the 5-FU-resistant, human colon carcinoma cell line SW620 (also known as CCL227), which overexpresses TS. Cells were maintained in RPMI supplemented with $10 \%$ fetal calf serum, $5 \%$ glutamine, $10 \%$ penicillin, $10 \%$ streptomycin and $1 \%$ kanamycin in a humidified $\mathrm{CO}_{2}$ incubator at $37^{\circ} \mathrm{C}$. All experiments were performed in exponentially growing cells.

\section{Drugs and chemicals}

Egg yolk phosphatidylcholine (PC), phosphatidylglycerol (PG), cholesterol (C), polyethylene glycol (PEG) covalently binded to phosphatidylethanolamine, 2'-deoxyinosine (d-Ino), 5-FU and $5^{\prime}$-dFUR were all purchased from Sigma (St Quentin, France). Di-kalium hydrogenous phosphate $\left(\mathrm{K}_{2} \mathrm{HPO}_{4}\right)$ buffer, tetrabutyl ammonium nitrate, acetonitrile, ether and methanol were bought from CarboErba (Milan, Italy). Dimethyl sulphoxide, the apoptosis kit and culture media were purchased from Euromedex (Souffelweyersheim, France). Tritiated 5-FU (12 $\mathrm{Ci} \mathrm{mmol}^{-1}$ ) was obtained from Moraveck Biochemical (Brea, CA, USA). All reagents were of analytical grade.

\section{Liposome preparation}

Liposomes ((5-FU $+\mathrm{d}-\mathrm{Ino})-\mathrm{L})$ were prepared by the classic thin film method (Olson et al, 1979). In brief, a lipid mixture composed of egg PC/PG/CHOL/PEG (molar ratios of $7.3: 0.73: 1.43: 0.47$ ) in methanol was evaporated under nitrogen in a round-bottom flask to form a dried thin film. This film was then hydrated with an isotonic carbonate solution $(\mathrm{pH} 4.2-7.4)$. The ratio - neutral phospholipid/cholesterol was $30 \%$ and when present, the negatively charged lipid was $10 \%$ of the neutral lipid. Multilamellar vesicles were formed by vortex mixing the lipid dispersions at room temperature. 5-Fluorouracil $(0.2 \mathrm{~mm})$ and d-Ino $(0.24 \mathrm{~mm})$ were encapsulated by incubation with the lipid film for $30 \mathrm{~min}$ at $37-40^{\circ} \mathrm{C}$. The resulting loaded PEG-liposomes were then shaken. Homogenous size distribution as SUV was achieved by $5 \mathrm{~min}$ $20 \mathrm{kHz}$ sonication with a probe. To remove the non-encapsulated drug, the liposomal suspension was ultracentrifuged at $70000 \mathrm{~g}$ at $4{ }^{\circ} \mathrm{C}$ for $16 \mathrm{~h}$, and the resulting pellet was re-suspended in either

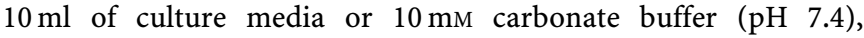
depending on its use (e.g. in vitro or in vivo). Finally, sterile liposomes were obtained after extrusion through PVDF filters (Durapore $0.22 \mu \mathrm{m}$, Millipore, Molsheim, France).

\section{Polydispersity study}

Diameter and particle size distribution were determined by dynamic laser light scattering using a Correlateur RTG submicron particle analyser (Sematech, Nice, France). Measurements were performed at $90^{\circ}$ angles, at room temperature. The mean diameter of the liposomes was estimated from the volume distribution curves given by the particle analyser.

\section{Encapsulation rate and releasing study}

Encapsulation rates of both 5-FU and d-Ino were performed by HPLC, using a previously published method (Fanciullino et al, 2005). Liposomal release of 5-FU and d-Ino was monitored by dialysis as described elsewhere (Fanciullino et al, 2005). Sampling was performed every $30 \mathrm{~min}$, up to $4 \mathrm{~h}$. The total amount of 5-FU and d-Ino released was determined by UV spectrophotometry at 248 nm (Beckman, Villepinte, France).

\section{Antiproliferative assays}

Cells were seeded at a density of $8 \times 10^{4}$ cells per well in 96-well plates. After overnight attachment, exponentially growing cells were exposed to increasing concentrations of 5-FU alone, 5-FU combined with free d-Ino, or the liposomal formulation [5-FU $+\mathrm{d}-$ Ino]-L, with gentle shaking for $24 \mathrm{~h}$. Next, drug was removed and the cells were allowed to grow in fresh medium for an additional $48 \mathrm{~h}$. After $72 \mathrm{~h}$ of discontinuous exposure, cell viability was evaluated using the classic colorimetric MTT assay (Alley et al, 1988). The $\mathrm{IC}_{50}$ was defined as the 5-FU concentration inhibiting $50 \%$ of cell growth.

\section{5-Fluorouracil tumoural metabolism study}

Exponentially growing cells were exposed to $1 \mu \mathrm{M}$ of tritiated 5-FU alone, combined with free d-Ino or as a liposomal preparation [5-FU $+\mathrm{d}-$-Ino]-L. After 3, 4 and $6 \mathrm{~h}$ exposure, cells were harvested, lysed into $70 \%$ methanol and cytosols were isolated by centrifugation (15000 r.p.m., $30 \mathrm{~min}$ ) and stored at $-80^{\circ} \mathrm{C}$ until analysis. Separation of 5-FU and its main metabolites was achieved using a HP1090 HPLC system (Agilent, Massy, France) coupled to a FloOne radioactive detector (Packard, Les Ulis, France) and equipped with an RP18 column (Agilent, France), followed by elution with a $\mathrm{K}_{2} \mathrm{HPO}_{4}$-TBAN/methanol gradient as described previously (Ciccolini et al, 2000b).

\section{Thymidylate synthase inhibition}

Thymidylate synthase activity was assessed as described previously (Chazal et al, 1997). Briefly, exponentially growing cells were exposed to various combinations of $100 \mu \mathrm{m}$ of 5-FU alone, 5-FU combined with $250 \mu \mathrm{M}$ d-Ino, or the liposomal formulation [5$\mathrm{FU}+\mathrm{d}$-Ino]-L for $12 \mathrm{~h}$. Inhibition of TS activity was evaluated at 8 , 24,48 and $72 \mathrm{~h}$. Cells were then harvested and the pellet was stored at $-80^{\circ} \mathrm{C}$ until further analysis. Thymidylate synthase activity was assayed following the standard Roberts' method based on tritiated $\mathrm{H}_{2} \mathrm{O}$ release from $\left[{ }^{3} \mathrm{H}\right]$ deoxyuridine monophosphate, in the presence of excess methylene tetrahydrofolate (Roberts, 1966).

\section{Cell death induction}

Cell-cycle distribution was monitored after exposing the cells for 48 and $72 \mathrm{~h}$ to $100 \mu \mathrm{M} \mathrm{5-FU,} \mathrm{5-FU} \mathrm{combined} \mathrm{with} 250 \mu \mathrm{M}$ of free d-Ino, or the [5-FU + d-Ino]-L combination at the same concentrations. Cells were washed two times with PBS, trypsinised and suspended in $70 \%$ methanol for $1 \mathrm{~h}$, at $4^{\circ} \mathrm{C}$. Next, they were centrifuged and immediately collected in $300 \mu \mathrm{l}$ PBS and $80 \mu \mathrm{l}$ of propidium iodide (PI), following the manufacturer's recommendations. Samples were analysed with FACScan flow cytometer (Beckman Coulter, Marseille, France) using Cell Quest software. The percentage of cell death was measured by detecting the sub$\mathrm{G}_{0} / \mathrm{G}_{1}$ peak in PI staining (Derzynkiewicz et al, 1992).

\section{Apoptosis studies}

Cells in the exponential phase were exposed to $100 \mu \mathrm{M}$ 5-FU alone, 5-FU with $250 \mu \mathrm{M}$ d-Ino, or the liposomal combination 
[5-FU + d-Ino]-L for 24, 48 and $72 \mathrm{~h}$. Cells were harvested, and early as well as late apoptotic changes were detected by simultaneous staining with Annexin and PI, using an Annexin V FITC staining kit (Sigma, St Quentin Fallavier, France). Cells were treated following the manufacturer's guidelines. FACS analysis was carried out in a FACScan flow cytometer (Becton Dickinson, Poisat, France) using the Cell Quest Software, and apoptosis measured in untreated cells was defined as $100 \%$.

\section{Drug monitoring study}

Comparison of the drug exposure levels achieved in animals treated with the free or encapsulated 5-FU $+\mathrm{d}$-Ino combination was performed. Six-week-old male wistar rats (Charles River, Lyon, France) were kept anaesthetised using $\mathrm{O}_{2} / \mathrm{NO}_{2}$ gas + isoflurane (TEM, Bordeaux, France) during the whole study. Body temperature was maintained at $37^{\circ} \mathrm{C}$ using a warming blanket. Animals ( $n=3$ /group) were administered by intraperitoneal injection with 5 -FU $\left(50 \mathrm{mg} \mathrm{kg}^{-1}\right)$ plus d-Ino $\left(120 \mathrm{mg} \mathrm{kg}^{-1}\right)$, either free or combined in the liposomal formulation. Sampling times were as following: T0, T60, T90 and T120 min. One millilitre of blood was withdrawn from jugular vein on heparinised tubes, and plasma was isolated by centrifugation at $5000 \mathrm{~g}$ for $10 \mathrm{~min}$. Samples were stored at $-20^{\circ} \mathrm{C}$ until analysed. 5-Fluorouracil and d-Ino plasma concentrations were determined by reverse-phase UV-HPLC as described previously, using 2-deoxyadenosine as internal standard (Fanciullino et al, 2005). Animal study was performed following animal welfare guidelines, and local animal ethics committee approval was obtained prior to starting the experiments.

\section{In vivo efficacy studies}

The antitumour efficacy of 5-FU alone, or in association with free d-Ino, or as the liposomal [5-FU + d-Ino]-L combination was investigated in the SW620 mouse xenograft model. Mouse care was in agreement with the animal welfare guidelines of our institution, and local animal ethics committee approval was obtained prior to starting the experiments. Four-week-old, female Swiss, nude mice ( $n=5$ per group, Charles River) were subcutaneously inoculated with $1 \times 10^{6}$ SW620 cells on the right flank. Ten days after implant, and once tumours had reached accurately measurable size, mice were treated with 5-FU by itself, 5-FU combined with free d-Ino, or with the [5-FU + d-Ino]-L form as follows: 5-FU: $50 \mathrm{mg} \mathrm{kg}^{-1}$, d-Ino and $120 \mathrm{mg} \mathrm{kg}^{-1}$. Drugs were administered intraperitoneally on a 3-times per week basis for 3 consecutive weeks (e.g., D1/D2/D3, D8/D9/D10 and D16/D17/D18). Tumour size was measured three times a week in three dimensions using vernier calipers, and tumour weight $(\mathrm{mg})$ was calculated using the following standard formula: mass $=\pi / 6 \times$ length $\times$ width $\times$ height (Waterhouse et al, 2005). Preliminary experiments with empty liposomes were conducted to confirm the absence of any in vivo antiproliferative activity. Animal weight was monitored as a marker of toxicity. Animals were euthanised whenever a $25 \%$ loss of initial weight was observed, or when tumours reached $2500 \mathrm{mg}$.

\section{RESULTS}

\section{Encapsulation rate and release studies}

Homogenous, 100-nm-diameter liposome populations were obtained. Encapsulation rates of 5-FU and d-Ino were $10.6 \pm 1.6$ and $26.2 \pm 5.3 \%$, respectively. Release curves for 5-FU and d-Ino had similar profiles $(n=5)$. Both were described by a polynomial equation (Figure 1). No significant difference was observed between the 180 and $240 \mathrm{~min}$ concentrations $(P>0.05, t$-test). Maximum, $100 \%$ release from the liposomes was reached after 4 - $h$ incubation for both drugs.

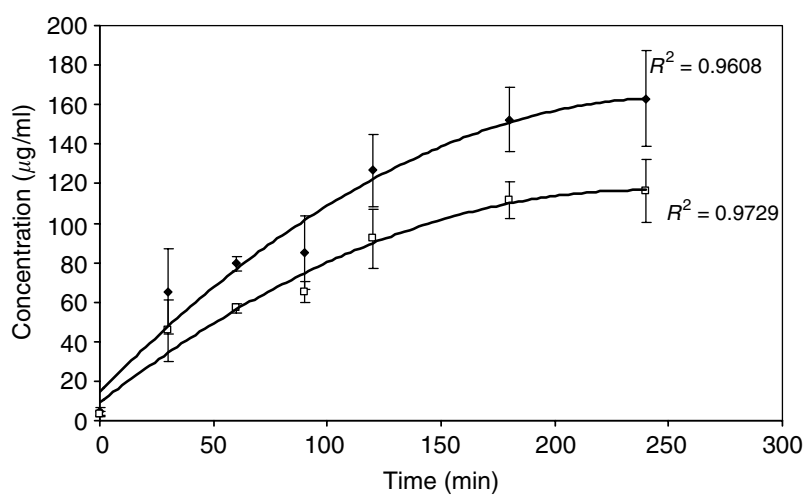

Figure I Monitoring of d-Ino ( ) and 5-fluorouracil (5-FU) ( $\square$ ) release from the liposomal [5-FU $+d-I n o]-L$ form. $d-I n o$ and 5-FU concentrations were measured at $248 \mathrm{~nm}$. Bars, s.d.

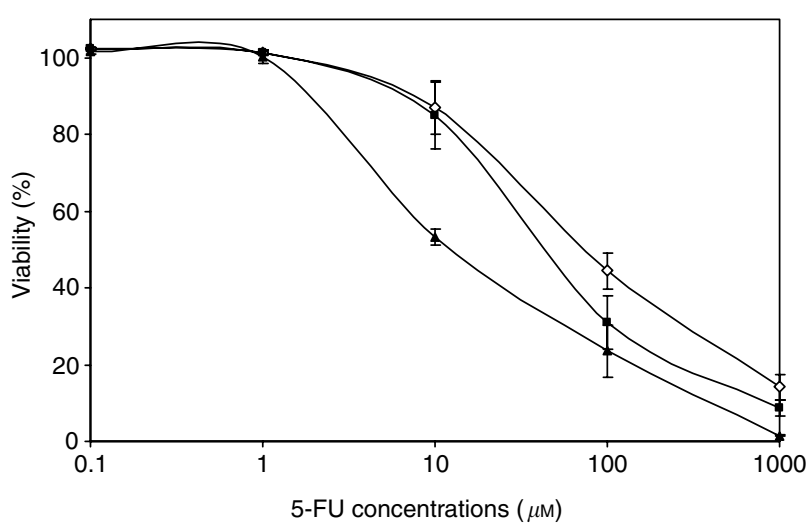

Figure 2 Modulation of 5-fluorouracil (5-FU) $(\diamond)$ cytotoxicity by free $\mathrm{d}$-Ino $(\mathbf{\square})$ or as the co-encapsulated [5-FU $+\mathrm{d}-$-Ino]-L form $(\mathbf{\Lambda})$. Cells were treated for $24 \mathrm{~h}$ and viability was measured by MTT testing after 48 extra hours of growth in drug-free medium. Bars, s.d.

\section{Modulation of antiproliferative activity}

Empty liposomes showed no in vitro cytotoxicity (data not shown). Results of cytotoxic studies are summarised in Figure 2. Combining 5-FU with either free d-Ino or used as a liposomal [5-FU + d-Ino]-L formulation led to a significant increase in cell sensitivity. The $\mathrm{IC}_{50} \mathrm{~s}$ for 5-FU alone, freely associated with d-Ino and encapsulated with d-Ino in a single liposome were $77 \pm 6,57 \pm 13$ and $48 \pm 6.4 \mu \mathrm{M}$, respectively $(n=3)$. At the $\mathrm{IC}_{50}$ level, use of free d-Ino caused a $26 \%$ improvement in 5 -FU efficacy, whereas the double-agent liposomal formulation caused a $37 \%$ increase in SW620 sensitivity. Similarly, cell response was further improved by 52 and $77 \%$ (free d-Ino and liposomal formulation, respectively) at $\mathrm{IC}_{20}$, and by 18 and $80 \%$ (free d-Ino/liposomes) at the $\mathrm{IC}_{80}$ levels.

\section{Modulation of 5-FU intracellular activation}

Intratumoural metabolic profiles of 5-FU used alone, combined with d-Ino or used as a liposomal formulation are displayed in Figure 3. When used alone, 5-FU anabolism took place via the RNA pathway, and little or no FdUMP was formed over the $3-6 \mathrm{~h}$ observation period. Combining d-Ino with 5-FU led to a striking change in the activation pattern of 5-FU, with activation occurring predominantly through the DNA pathway, resulting in subsequent intracellular accumulation of fluoro-deoxynucleotides. Overall, anti-TS FdUMP synthesis was increased from 83 d.p.m. mg ${ }^{-1}$ protein (5-FU alone) to 3199 d.p.m. $\mathrm{mg}^{-1}$ (5-FU + d-Ino + 3801\%) 

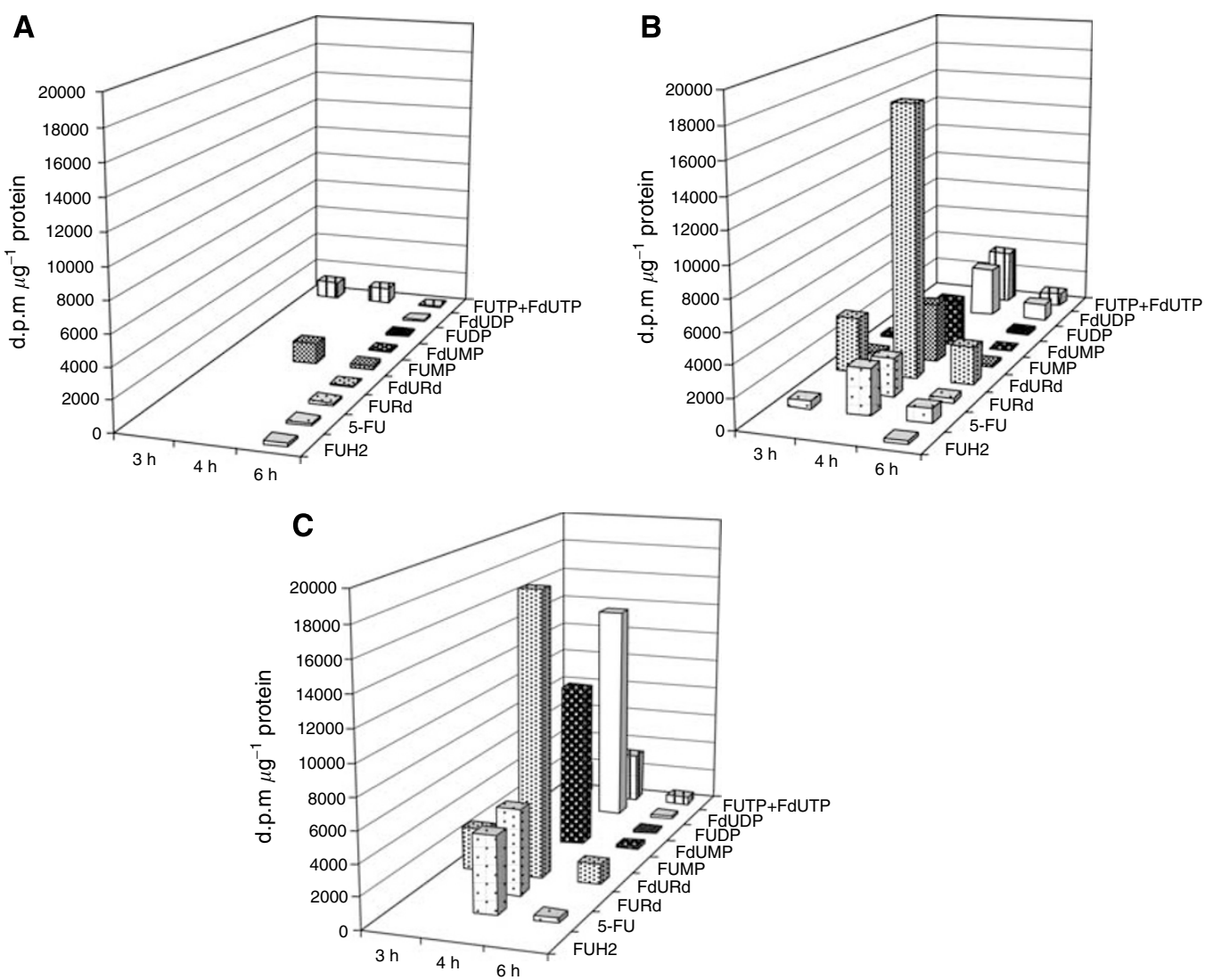

Figure 3 Monitoring of the intratumoural activation of tritiated 5-fluorouracil (5-FU) alone $(\mathbf{A})$, associated with free d-Ino (B), or as a liposomal $[5-F U+d-I n o]-L$ combination $(\mathbf{C})$. Data are from one representative experiment. FUH2 = dihydrofluorouracil, FURd = fluorouridine, FUMP $=$ fluorouridine monophosphate, FUDP = fluorouridine diphosphate, FUTP=fluorouridine triphosphate, FdURd=fluorodeoxyuridine, FdUMP = fluorodeoxyuridine monophosphate, FdUDP = fluorodeoxyuridine diphosphate, FdUTP = fluorodeoxyuridine triphosphate.

and to 11276 d.p.m. $\mathrm{mg}^{-1}$ (liposomal combination, + $13561 \%$ ). When considering the total cytosolic amount of unchanged 5-FU and metabolites formed, data showed that exposing SW620 cells to the [5-FU + d-Ino]-L combination led to a $36 \%$ increase of drug uptake as compared with the free form combination.

\section{Thymidylate synthase inhibition study}

A significant improvement in TS inhibition was observed both with free d-Ino and with the encapsulated formulation (Figure 4). Thymidylate synthase activity was diminished by $96 \%$ after $8 \mathrm{~h}$ in cells exposed to 5-FU $+\mathrm{d}$-Ino as compared to 5-FU alone. The liposomal formulation further improved this inhibition level by $61 \%$, with an eventual $98 \%$ decrease in TS activity $(n=3)$.

\section{Cell-cycle analysis}

Monitoring of the sub- $\mathrm{G}_{0} / \mathrm{G}_{1}$ population at $48 \mathrm{~h}$ after PI staining is displayed in Figure 5. Results revealed a $324 \%$ higher induction of cell death by 5 -FU when associated with free d-Ino, and a $408 \%$ increase with the liposomal form, as compared with 5-FU alone. At $72 \mathrm{~h}$, increases in cell death of 150 and $169 \%$, respectively with d-Ino or liposomal formulations $(n=3)$ were observed.

\section{Apoptosis studies}

A greater induction of both early and late apoptosis was observed in SW620 exposed to FU modulated with free d-Ino, or the coencapsulated form (Figure 6). Early apoptosis induction was increased by 235,103 and $136 \%$ at 24,48 and $72 \mathrm{~h}$, respectively

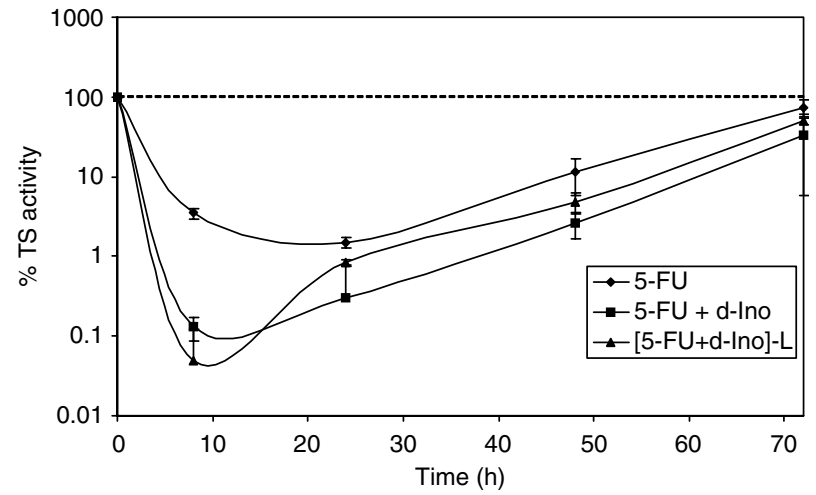

Figure 4 Potentiation of thymidylate synthase (TS) inhibition by 5-fluorouracil (5-FU) alone, combined with free d-Ino or with the liposomal [5-FU + d-Ino]-L association. Cells were exposed for $24 \mathrm{~h}$ to $100 \mu \mathrm{M}$ 5-FU alone, in combination with $250 \mu \mathrm{M}$ d-Ino or to the encapsulated association.

(free d-Ino) and by 326, 268 and 219\% with the liposomal form, as compared with 5-FU alone. Similarly, late apoptosis was increased by 92,119 and $138 \%$ after 24, 48 and $72 \mathrm{~h}$ (free d-Ino) and by 159 , 206 and $219 \%$ with the encapsulated form, as compared with the use of standard 5-FU $(n=4)$.

\section{Drug monitoring study}

Monitoring of 5-FU and d-Ino in plasma was performed after administration of these both drugs, injected either free or as a 


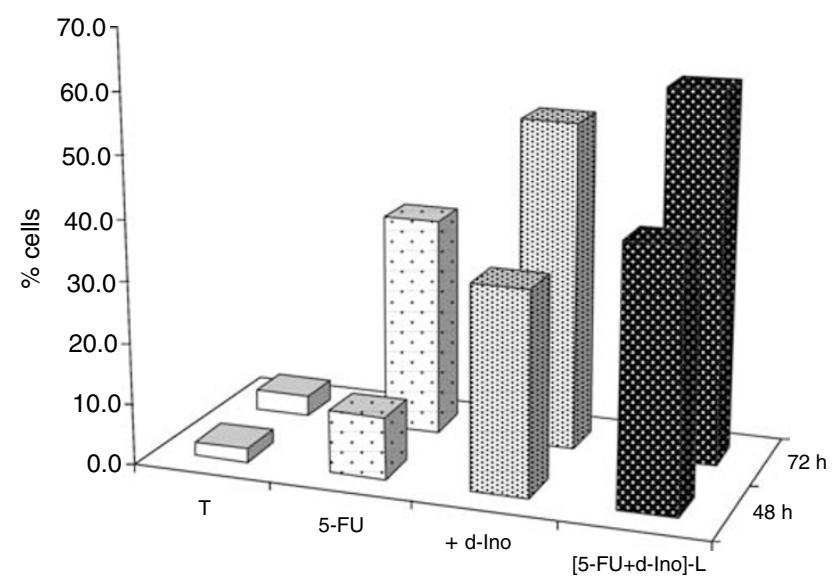

Figure 5 Cell-death induction by 5 -fluorouracil (5-FU) alone, combined with free d-Ino or with the liposomal $[5-\mathrm{FU}+\mathrm{d}-\mathrm{Ino}]-\mathrm{L}$ association. Cells were exposed for $24 \mathrm{~h}$ to $100 \mu \mathrm{M} 5$-FU alone or associated with $250 \mu \mathrm{M}$ $\mathrm{d}$-Ino. Cell death was measured at 48 and $72 \mathrm{~h}$ after propidium iodide (PI) staining and flow-cytometry analysis.

liposomal combination. Due to analytical interferences with merging endogenous peaks, 5-FU concentrations remained below our limit of detection, regardless of the formulation used. Conversely, d-Ino was fully measurable over the 60-120 min period and showed circulating concentrations up to $139 \%$ higher when administered as liposomes, as compared with the free form. At $120 \mathrm{~min}, 470 \mathrm{ng} \mathrm{ml}^{-1}$ of d-Ino was still measured in rats of the liposome group, whereas no modulator was detected anymore in animals treated with the free 5-FU $+\mathrm{d}$-Ino association.

\section{In vivo efficacy studies}

Treatment with the empty liposomes showed no impact on tumour growth as compared to untreated animals (data not shown). At the conclusion of the study, tumour size was reduced by $28 \%$ (NS), $23 \%(\mathrm{NS})$ and $74 \%(P<0.05)$ in mice treated with 5 -FU alone, 5 -FU with free d-Ino or the [5-FU $+\mathrm{d}$-Ino]-L formulation, respectively (Figure 7). No signs of toxicity were observed in these animals, regardless of the treatment modality, and no statistical differences were found in animal weights among the different groups (data not shown). When compared to controls, survival time was increased by $25 \%$ in the 5-FU-treatment group ( 20 vs 16 days), $56 \%$ in the group treated with the 5-FU $+\mathrm{d}$-Ino combination, and by $94 \%$ in animals treated with the liposomal formulation $(P<0.05$, Figure 8$)$.

\section{DISCUSSION}

Liposomes can help reduce the toxicity of anticancer drugs, while maintaining or enhancing their efficacy (Di Paolo, 2004). Despite these promising features, with regard to improving of the therapeutic index of anticancer chemotherapies, only doxorubicine $\left(\right.$ Caelyx $\left.{ }^{\mathbb{R}}\right)$ has been marketed to date as a liposomal formulation. In addition to anthracyclines, several experimental or clinical studies involving encapsulated gemcitabine, methotrexate and platinum derivatives, have been reported over the past 20 years, but thus far, none of them has made its way to the bedside, in a routine, clinical setting (Doddoli et al, 2005; Stathopoulos et al, 2006; Brusa et al, 2007).

Several mechanical and biological mechanisms support the passive tumoural selectivity of liposomes. Sustained release rates, for instance, may enhance antitumour efficacy through an enhanced permeability and retention effect, via a better utilisation
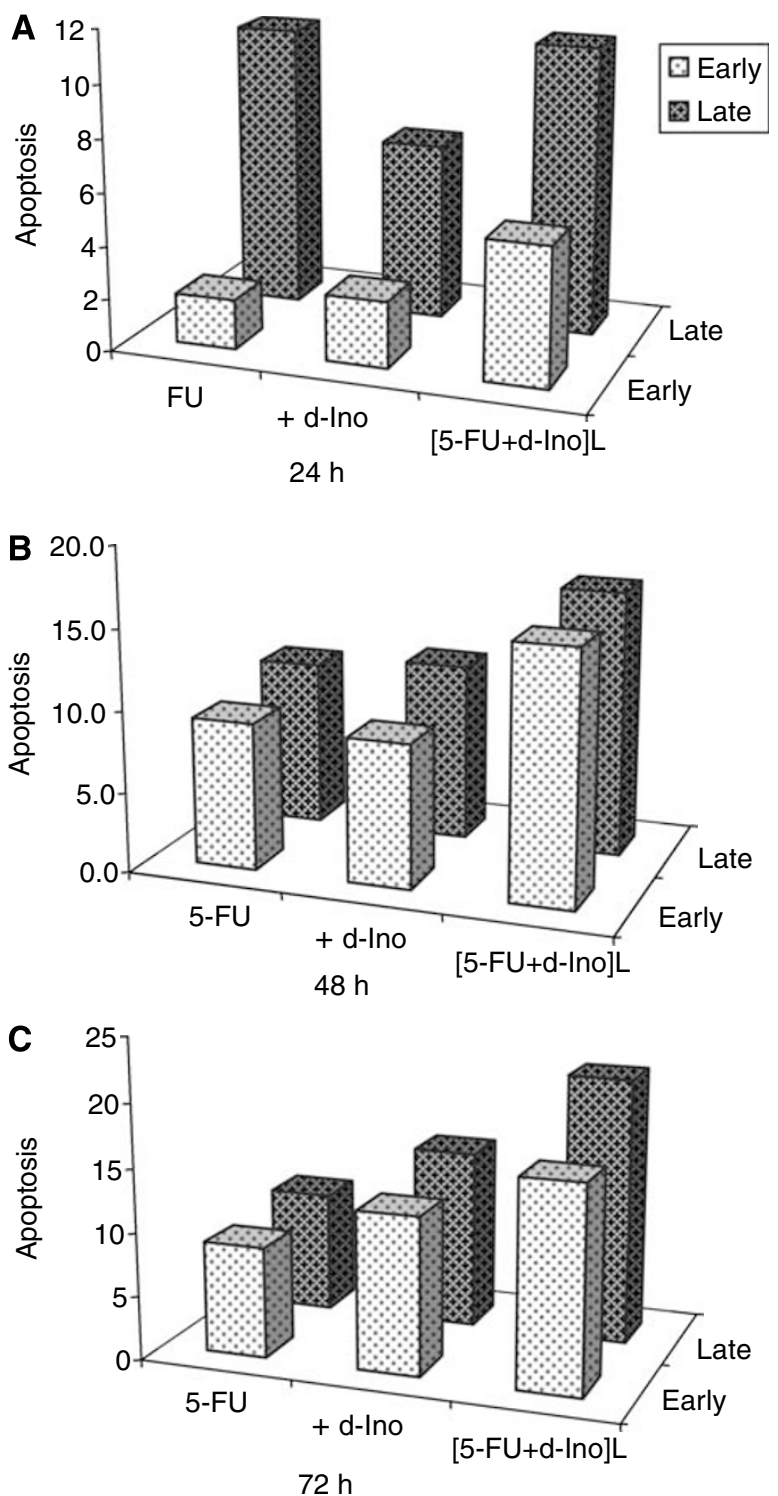

Figure 6 Enhancement of 5-fluorouracil (5-FU)-induced apoptosis. SW620 cells were exposed to $100 \mu \mathrm{M}$ of 5-FU alone or combined with $250 \mu \mathrm{M} \mathrm{d}$-Ino, either free or as a liposomal combination. Early and late apoptosis were discriminated by propidium iodide (PI)/Annexin $\vee$ double staining with subsequent flow-cytometry analysis. Cells were treated for $24 \mathrm{~h}(\mathbf{A}), 48 \mathrm{~h}(\mathbf{B})$ and $72 \mathrm{~h}(\mathbf{C})$.

of the vascular abnormalities of solid tumours, eventually leading to a greater tumoural uptake (Maeda, 2001). Defects in the capillary endothelium of tumour vasculature are typically in the size range of 200-600 nm and therefore, liposomes of $100 \mathrm{~nm}$ in diameter, as generated in this study, can efficiently extravasate and accumulate within the tumour interstitial space, thus providing additional specificity (Yuan et al, 1995). Besides their size, intratumoural accumulation of macromolecules is further enhanced by carrier systems displaying reduced release rates and long circulating times (Papahadjopoulos et al, 1991; Yuan et al, 1994). To slow down the release rate of our liposomes and improve their bioavailability, cholesterol and PEG were used to extend stability via greater membrane rigidity and a 'stealth' passage through the liver. Additionally, negatively charged lipids were also used in this study to avoid 


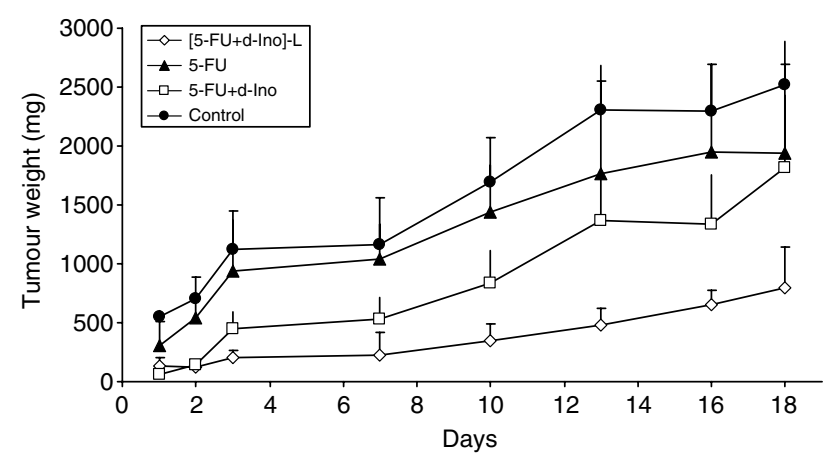

Figure 7 Effects of the liposomal association [5-FU $+d-I n o]-L$ on SW620 tumour growth in nude mice. Animals ( $n=5$ per group) were subcutaneously transplanted with SW620 tumoural cells and administered for three consecutive days, over three consecutive weeks with each of the following: carbonate (daily intraperitoneally (i.p.)); 5-fluorouracil (5-FU) $\left(50 \mathrm{mg} \mathrm{kg}^{-1}\right.$ daily i.p.) alone or combined with d-Ino (I $20 \mathrm{mg} \mathrm{kg}^{-1}$ daily i.p.) or as the [5-FU +d-Ino]-L formulation $\left(50+120 \mathrm{mg} \mathrm{kg}^{-1}\right.$, respectively). Bars, s.d.

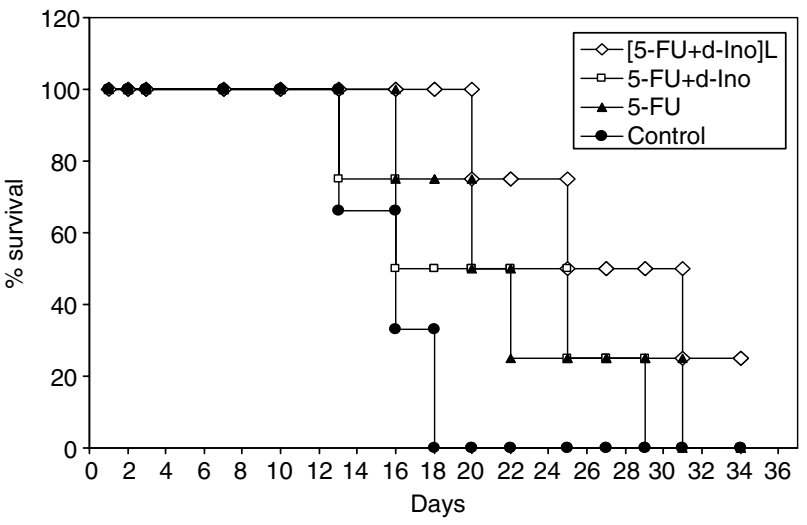

Figure 8 Kaplan-Meier representation of tumour-bearing mice's survival treated either with 5-fluorouracil (5-FU) alone, 5-FU + d-Ino, or with the $[5-\mathrm{FU}+\mathrm{d}-\mathrm{Ino}]-\mathrm{L}$ combination, as compared with untreated animals.

liposomal aggregation, eventually permitting a better stability. Consequently, drug monitoring of d-Ino revealed circulating concentrations systematically higher when injected as a part of the liposomal formulation, as compared with its free counterpart. Beside these higher plasma levels, sustained exposure to the drug was achieved, as liposomal d-Ino remained fully detectable $2 \mathrm{~h}$ after administration, whereas free d-Ino was totally cleared. Despite its extremely widespread use in clinical oncology, few reports have focused on encapsulating 5-FU in simple carriers, probably as a result of its polar and amphotereous properties that render it particularly difficult to entrap in standard liposomes (Simmons and Krame, 1977; Nii and Ishii, 2005). However, as a prodrug, 5-FU presents an opportunity to increase its therapeutic efficacy by combining it with biochemical modulators that can improve its intratumoural activation pattern. Similarly, the strategy of combining encapsulated anticancer drugs with a modulator has been established, for example, in the case of doxorubicin combined with valspodar. However, these two drugs were not encapsulated in a single liposome (Fracasso et al, 2005). The specific, well-tolerated modulator, d-Ino, has been identified as a promising agent that can improve the antitumour action of 5-FU (Ciccolini et al, 2000b, 2001). Despite significant achievements in enhancing 5 -FU efficacy, in various experimental models, in vivo handling of d-Ino was rendered difficult as a result of dramatic erythrocytic catabolism. To overcome this, we developed previously the first encapsulated formulation of liposomal d-Ino. We next, demonstrated its ability to modulate 5-FU efficacy in mouse xenografts (Ciccolini et al, 2000b). In light of these considerations, the aim of the present study was to reverse 5-FU resistance in vitro and in vivo through a two-pronged strategy: combining 5-FU with the d-Ino modulator, and treating tumour cells with our new, stealth liposomal formulation comprised of the aforementioned combination. The canonical SW620 line was chosen in this study because it overexpresses TS and, therefore, proves to be highly resistant to 5-FU, thus miming the major cause of treatment failure in clinical settings (Ciccolini et al, 2000b). We showed that it was possible to reproducibly co-encapsulate both 5 -FU and its modulator, with encapsulation rates and release profiles comparable to the pharmacodynamics of these compounds, showing that intratumoural formation of active FdUMP in the 3-6h time window was associated with a maximum efficacy in digestive cancer models (Ciccolini et al, 2000b, 2001). However, co-encapsulation rates of both 5-FU and its modulator were relatively poor (11 and $26 \%$, respectively). Such a moderate encapsulation rate for 5-FU is not surprising when considering the polar and amphoterous properties of this drug, that render its handling quite difficult when preparing standard pegylated liposomes, as used here (Nii and Ishii, 2005). Indeed, our strategy was to develop a stealth delivery system as basic and as simple as possible, to easily standardise a fabrication process that could be performed in most laboratories equipped with standard apparatus and reagents.

In the current study, encapsulation rates proved to be highly reproducible throughout time (e.g., $<2 \%$ for 5-FU), thus suggesting little batch-to-batch variation, likely to bias subsequent experiments. In vitro, reversal of the resistant profile of our model was achieved, with increases in both cell death and apoptosis induction, as well as marked increases in sensitisation (e.g., $+80 \%$ at $\mathrm{IC}_{20}$ ) of the SW620 cells to 5-FU. Further experiments confirmed that this increase in efficacy was due to a remarkable switch from the RNA to the DNA activation pathway, with increased formation of active FdUMP when 5-FU was modulated with d-Ino. Subsequent examination of TS activity, as a pharmacological end point, showed profound and sustained inhibition of this target, in cells exposed to the liposomal combination. Additionally, we observed that besides the preferential activation towards FdUMP, a nearly $40 \%$ increase in overall 5 -FU cytosolic levels was achieved in cells treated with the liposomal formulation, thus probably adding to the higher cytotoxicity effect that was subsequently measured. Interestingly, similar reversal of resistance to 5-FU was also achieved in mice. When used as monotherapy, 5-FU failed to reduce tumour growth as compared with untreated animals. It is noteworthy that combining 5-FU with free d-Ino hardly improved efficacy in this animal study, probably due to the relatively low doses of modulator used $\left(120 \mathrm{mg} \mathrm{kg}^{-1}\right)$ and considering d-Ino's dramatic catabolism and the dosage that is normally required $\left(3.2 \mathrm{~g} \mathrm{~kg}^{-1}\right)$ to achieve modulating effects in vivo (Ciccolini et al, 2000b, 2001). Conversely, [FU + d-Ino]-L caused a $69 \%$ reduction in tumour size when compared with untreated animals, and a significant $57 \%$ reduction when compared with 5-FU alone. Of note, this increase in efficacy was not accompanied with extra toxicities and all animals showed excellent tolerance, thus indicating an obvious improvement in the therapeutic index of 5-FU. In concordance with the increased antitumoural efficacy and good tolerance, median survival time was nearly doubled in animals treated with our liposomal formulation, compared with standard 5-FU, thus demonstrating that chemoresistance to 5-FU could indeed be overcome. 


\section{CONCLUSION}

Drug resistance is a major cause for clinical failure of chemotherapies for digestive cancers. Here, we demonstrate that it is possible to render chemosensitive an experimental model initially highly resistant to 5-FU, a drug used extensively in colorectal cancer. Our dual-agent liposomal formulation caused, through a more effective activation of the 5-FU prodrug into active metabolites interfering with TS, an increase in the induction of both cell death and apoptosis. When examined in tumour-bearing mice, this new formulation led to a striking improvement in treatment efficacy and subsequent survival in animals, thus

\section{REFERENCES}

Alley MC, Scudiero DA, Monks A, Hursey ML, Czerwinski MJ, Fine DL, Abbott BJ, Mayo JG, Shoemaker RH, Boyd MR (1988) Feasability of drug screening with panels of human tumor cell lines using a microculture tetrazolium assay. Cancer Res 48: 589-601

Blanquicett C, Saif MW, Buchsbaum DJ, Eloubeidi M, Vickers SM, Chhieng DC, Carpenter MD, Sellers JC, Russo S, Diasio RB, Johnson MR (2005) Antitumor efficacy of capecitabine and celecoxib in irradiated and lead-shielded, contralateral human BxPC-3 pancreatic cancer xenografts: clinical implications of abscopal effects. Clin Cancer Res 11: $8773-8781$

Boyer J, McLean EG, Aroori S, Wilson P, McCulla A, Carey PD, Longley DB, Johnston PG (2004) Characterization of p53 wild-type and null isogenic colorectal cancer cell lines resistant to 5-fluorouracil, oxaliplatin, and irinotecan. Clin Cancer Res 10: 2158-2167

Brusa P, Immordino ML, Rocco f, Cattel L (2007) Antitumor activity and pharmacokinetics of liposomes containing lipophilic gemcitabine prodrugs. Anticancer Res 27: 195-199

Canman C, Tang HY, Normolle DP, Lawrence TS, Maybaum J (1992) Variations in patterns of DNA damage induced in human colorectal tumor cells by 5 -fluorodeoxyuridine: implications for mechanisms of resistance and cytotoxicity. Proc Natl Acad Sci USA 89: 10474-10478

Chazal M, Cheradame S, Formento JL, Francoual M, Formento P, Etienne MC, Francois E, Richelme H, Mousseau M, Letoublon C, Pezet D, Cure H, Seitz JF, Milano G (1997) Decreased folylpolyglutamate synthetase activity in tumors resistant to fluorouracil-folinic acid treatment:clinical data. Clin Cancer Res 3: 553-557

Ciccolini J, Cuq P, Evrard A, Giacometti S, Pelegrin A, Aubert C, Cano JP, Iliadis A (2001) Combination of thymidine phosphorylase gene transfer and deoxyinosine treatment greatly enhances 5-fluorouracil antitumor activity in vitro and in vivo. Mol Cancer Ther 1: 133-139

Ciccolini J, Evrard A, Cuq P (2004) Thymidine phosphorylase and fluoropyrimidines efficacy: a Jekyll and Hyde story. Curr Med Chem Anticancer Agents 4: 71-81

Ciccolini J, Peillard L, Aubert C, Formento P, Milano G, Catalin J (2000a) Monitoring of the intracellular activation of 5-fluorouracil to deoxyribonucleotides in HT29 human colon cell line: application to modulation of metabolism and cytotoxicity study. Fundam Clin Pharmacol 14: $147-154$

Ciccolini J, Peillard L, Evrard A, Cuq P, Aubert C, Pelegrin A, Formento P, Milano G, Catalin J (2000b) Enhanced antitumor activity of 5 -fluorouracil in combination with $2^{\prime}$-deoxyinosine in human colorectal cell lines and human colon tumor xenografts. Clin Cancer Res 6: $1529-1535$

De Bruin M, van Capel T, Smid K, van der Born K, Fukushima M, Hoekman K, Pinedo HM, Peters GJ (2004) Role of platelet derived endothelial cell growth factor/thymidine phosphorylase in fluoropyrimidine sensitivity and potential role of deoxyribose-1-phosphate. Nucleosides Nucleotides Nucleic Acids 23: $1485-1490$

Derzynkiewicz Z, Bruno S, Del Bino G, Gorczyca W, Hotz MA, Lassota P, Traganos F (1992) Features of apoptotic cells measured by flow cytometry. Cytometry 13: 95-808

Di Paolo A (2004) Liposomal anticancer therapy: pharmacokinetic and clinical aspects. J Chemother 16: $90-93$

Diasio RB, Harris BE (1989) Clinical pharmacology of 5-fluorouracil. Clin Pharmacokinet 16: 215-237

Doddoli C, Ghez O, Barlesi F, D'journo B, Robitail S, Thomas P, Clerc T (2005) In vitro and in vivo methotrexate disposition in alveolar suggesting that reversal of chemoresistance could be achieved following our combined (encapsulation + modulation) strategy.

\section{ACKNOWLEDGEMENTS}

We thank Mr Edmond Oliva at the GEFLUC Marseille-Provence (Groupement des Entreprises Françaises dans la Lutte contre le Cancer), for supporting this study in 2006 and 2007. Additionally, this work was partly supported by a grant from the Foundation Philippe Daher, Marseille, France. macrophages: comparison of pharmacokinetic parameters of two formulations. Int J Pharm 297: 180-189

Evrard A, Cuq P, Ciccolini J, Vian L, Cano JP (1999) Increased cytotoxicity and bystander effect of 5-fluorouracil and 5-deoxy-5-fluorouridine in human colorectal cancer cells transfected with thymidine phosphorylase. Br J Cancer 80: 1726-1733

Fanciullino R, Evrard A, Cuq P, Giacometti S, Peillard L, Mercier C, Aubert C, Milano G, Ciccolini J (2006) Genetic and biochemical modulation of 5-fluorouracil through the overexpression of thymidine kinase: an invitro study. Anticancer Drugs 17: 463-470

Fanciullino R, Giacometti S, Aubert C, Fina F, Martin PM, Piccerelle P, Ciccolini J (2005) Development of stealth liposome formulation of 2 -deoxyinosine as 5-fluorouracil modulator: in vitro and in vivo study. Pharm Res 22: $2051-2057$

Fracasso PM, Blum KA, Ma MK, Tan BR, Wright LP, Goodner SA, Fears CL, Hou W, Arquette MA, Picus J, Denes A, Mortimer JE, Ratner L, Ivy SP, McLeod HL (2005) Phase I study of pegylated liposomal doxorubicin and the multidrug-resistance modulator, valspodar. $\mathrm{Br}$ J Cancer 93: 46-53

Johnston PG, Lenz HJ, Leichman CG, Danenberg KD, Allegra CJ, Danenberg PV, Leichman L (1995) Thymidylate synthase gene and protein expression correlate and are associated with response to 5-fluorouracil in human colorectal and gastric tumors. Cancer Res 55: $1407-1412$

Langley DB, Harkin DP, Johnston PG (2003) 5-fluorouracil mechanisms of action and clinical strategies. Nat Rev Cancer 3: 330-338

Maeda H (2001) The enhanced permeability and retention (EPR) effect in tumor vasculature: the key role of tumor-selective macromolecular drug targeting. Adv Enzyme Regul 41: 189-207

Nii T, Ishii F (2005) Encapsulation efficiency of water-soluble and insoluble drugs in liposomes prepared by the microencapsulation vesicle method. Int J Pharm 298: 198-205

Olson F, Hunt CA, Szoka FC, Vail WJ, Papahadjopoulos D (1979) Preparation of liposomes of defined size distribution by extrusion through polycarbonate membranes. Biochim Biophys Acta 557: 9-23

Papahadjopoulos D, Allen TM, Gabizon A, Mayhew E, Matthay K, Huang SK, Lee SD, Woodle MC, Lasic DD, Redemann C (1991) Sterically stabilized liposomes: improvements in pharmacokinetics and antitumor therapeutic efficacy. Proc Natl Acad Sci USA 88: 11460-11464

Peters GJ, Backus HH, Freemantle S, van Triest B, Codacci-Pisanelli G, van der Wilt CL, Smid K, Lunec J, Calvert AH, Marsh H, McLeod HL, Bloemena E, Meijer s, Jansen G, van Groeningen CJ, Pinedo HM (2002) Induction of thymidylate synthase as a 5-fluorouracil resistance mechanism. Biochim Biophys Acta 1587: 194-205

Pinedo HM, Peters GJ (1988) Fluorouracil: biochemistry and pharmacology. J Clin Oncol 6: 1653-1664

Roberts D (1966) An isotopic assay for thymidylate synthetase. Biochemistry 5: 3546-3548

Schwartz EL, Baptiste N, Megati S, Wadler S, Otter BA (1995a) 5-Ethoxy-2'deoxyuridine, a novel substrate for thymidine phosphorylase, potentiates the antitumor activity of 5-fluorouracil when used in combination with interferon, an inducer of thymidine phosphorylase expression. Cancer Res 55: $3543-3550$

Schwartz EL, Baptiste N, Wadler S, Makower D (1995b) Thymidine phosphorylase mediates the sensitivity of human colon carcinoma cells to 5-fluorouracil. J Biol Chem 270: 19073-19077

Simmons SP, Krame PA (1977) Liposomal entrapment of floxuridine. J Pharm Sci 66: $984-986$ 
Stathopoulos GP, Boulikas T, Vougiouka M, Rigatos SK, Stathopoulos JG (2006) Liposomal cisplatin combined with gemcitabine in pretreated advanced pancreatic cancer patients: a phase I-II study. Oncol Rep 15: $1201-1204$

Waterhouse DN, Madden TD, Cullis PR, Bally MB, Mayer LD, Webb MS (2005) Preparation, characterization, and biological analysis of liposomal formulations of vincristine. Methods Enzymol 391: 40-57

Yuan F, Dellian M, Fukumura D, Leunig M, Berk DA, Torchilin VP, Jain RK (1995) Vascular permeability in a human tumor xenograft : molecular size dependence and cutoff size. Cancer Res 55: 3752-3756

Yuan F, Leunig S, Huang SK, Berk DA, Papahadjopoulos D, Jain RK (1994) Microvascular permeability and interstitial penetration of sterically stabilized (stealth) liposomes in a human tumor xenograft. Cancer Res 54: $3352-3356$ 